\title{
Avaliação de desempenho hidráulico de sarjetas no sistema de drenagem urbana: um estudo no bairro Aldeota, em Fortaleza (CE)
}

Lucas Florêncio da Cunha Teixeira lucasfengcivil@gmail.com Universidade Federal do Ceará (UFC)

Anísio de Sousa Meneses Filho anisiomeneses@unifor.br Universidade de Fortaleza (Unifor)

\section{Street gutters' hydraulic performance evaluation in urban drainage system: a study in Aldeota area, in Fortaleza city, state of Ceará}

\section{Evaluación de rendimiento hidráulico de alcantarillas en el sistema de drenaje urbano: un estudio en el barrio Aldeota, en Fortaleza (CE)}

\section{Évaluation des performances hydrauliques des caniveaux dans le système de drainage urbain: une étude dans l'arrondissement Aldeota, à Fortaleza, Brésil}

\section{Resumo}

Este trabalho se destina a realizar uma avaliação da capacidade hidráulica de sarjetas urbanas no quesito de condução de águas pluviais considerando duas situações distintas: a de projeto, em que são obedecidos os parâmetros hidráulicos e hidrológicos de dimensionamento, e aquela encontrada em campo, em que são observadas diversas intervenções que desfiguram esse elemento e, portanto, prejudicam a sua capacidade de condução requerida. Dessa forma, foi selecionada uma área composta por oito quadras no bairro Aldeota, em Fortaleza (CE), com alta densidade demográfica. Foram feitas visitas à área de estudo, para locação das bocas de lobo, e à Secretaria de Infraestrutura de Fortaleza, para obtenção de material cartográfico para dar suporte à realização dos cálculos. Com esses dados, foram feitos os cálculos de vazão limite para as duas situações, podendo-se observar que, com a simulação das intervenções encontradas em campo pela redução da área transversal das sarjetas, a área pretensamente drenada passa a ter maior risco de alagamento. Assim, evidencia-se que a execução física em estrita conformidade ao projeto constitui fator determinante para o seu efetivo desempenho.

Palavras-chave: Drenagem urbana. Sarjetas urbanas. Condução hidráulica. 
constitutes a determining factor for its effective performance.

Keywords: Urban drainage. Street gutters. Hydraulic conduction.

\section{Resumen}

Este trabajo tiene el objetivo de evaluar la capacidad hidráulica de alcantarillas urbanas en la cuestión de conducción de aguas pluviales considerando dos situaciones distintas: la del proyecto, en que son obedecidos los parámetros hidráulicos e hidrológicos de dimensionamiento, y aquella encontrada en campo, en que son observadas muchas intervenciones que desfiguran este elemento $\mathrm{y}$, por lo tanto, perjudican su capacidad de conducción requerida. Así, fue seleccionado un área compuesto por ocho cuadras en el barrio Aldeota, en Fortaleza (CE), con alta densidad demográfica. Los locales de estudio fueron visitados para ubicación de las alcantarillas, y la Secretaria de Infraestructura de Fortaleza, para obtención de material cartográfico para dar soporte a la realización de los cálculos. Con estos datos, fueron hechos los cálculos de caudal límite para las dos situaciones, observándose que, con la simulación de las intervenciones encontradas en campo por la reducción del área transversal de las alcantarillas, el área presuntamente drenada pasa a tener mayor riesgo de inundación. De este modo, se evidencia que la ejecución física en estricta conformidad al proyecto constituye factor determinante para su rendimiento efectivo.

Palabras-clave: Drenaje urbano. Alcantarillas urbanas. Conducción hidráulica.

\section{Résumé}

L'objectif de ce travail est de réaliser une évaluation de la capacité hydraulique des caniveaux urbains en termes de conduction des eaux pluviales en considérant deux situations distinctes: 1) la conception du projet, dans laquelle les paramètres hydrauliques et hydrologiques de dimension sont respectés et 2) celle qui est trouvée au le terrain, dans laquelle sont observées plusieurs interventions qui défigurent cet élément et, par conséquent, altèrent sa capacité nécessaire de conduction. Ainsi, On a sélectionné une zone avec haute densité démographique, composée de huit blocs dans l'arrondissement Aldeota, à Fortaleza, Brésil. Des visites ont été effectuées dans la zone d'étude, pour louer des bouches de loups. On a aussi visité la Secrétariat des infrastructures de Fortaleza, pour obtenir le matériel cartographique pour qu'on puisse en appuyer des calculs. Avec ces données, des calculs de débit limite ont été effectués pour les deux situations, et on peut constater qu'avec la simulation des interventions trouvées au terrain en réduisant la surface transversale des caniveaux, la zone supposée drainée devient plus à risque d'inondation. Ainsi, il est évident que l'exécution physique en stricte conformité avec le projet est un facteur déterminant pour sa performance effective.

Mots-clés: Drainage urbain. Caniveaux urbains. Conduction hydraulique.

\section{Introdução}

A importância sanitária do manejo das águas pluviais, segundo o Ministério da Saúde (BRASIL, 2007, p. 287), se dá como uma forma de escoar a água no intuito de combater a propagação de doenças de veiculação hídrica.

De forma geral, os centros urbanos tendem a se expandir sem a devida atenção aos estudos necessários para impactar de forma mais amena o sistema natural pré-existente e, portanto, influenciando diretamente no comportamento hidrológico das bacias hidrográficas, agravando ainda mais o cenário de cobertura de saneamento básico. (TEIXEIRA, 2017, p. 15). Dessa forma, com a redução de áreas permeáveis, faz-se necessária a concepção adequada de projeto para drenar o volume de escoamento excedente. 
Com essa expansão territorial, sem fiscalização para direcionar o adequado uso e ocupação do solo, os problemas de alagamento e enchentes agravam-se ao longo das linhas naturais de escoamento superficial, seguindo a topografia da cidade. (LIMA, 2019, p. 22).

Entre os elementos de microdrenagem, destacam-se as sarjetas, foco deste trabalho, pelo fato de serem o primeiro elemento com o qual as águas pluviais entram em contato. Além disso, de forma geral, nos centros urbanos brasileiros há negligência no que diz respeito à importância desse elemento.

As sarjetas urbanas devem ser concebidas de forma a permitirem a adequada condução das águas pluviais aos demais elementos de microdrenagem urbana dimensionados pelos projetistas. Entretanto há fatores que prejudicam o seu correto funcionamento, como: o subdimensionamento, relacionado a problemas de projeto ou de concepção; a má execução, que pode estar associada, também, à execução do concreto asfáltico adjacente, podendo haver deslizamento e redução da seção da sarjeta; e a manutenção após a finalização do serviço de implantação desse elemento, que tem relação com a limpeza correta do lixo despejado sobre as sarjetas e também com a conservação e reparo de danos causados pelo uso ao longo do tempo. (TEIXEIRA, 2017, p. 16). Portanto, a seção transversal prevista em projeto deve ser obedecida na execução, assim como mantida durante a vida útil da estrutura.

No município de Fortaleza, devido às exigências da Lei Federal n. ${ }^{\circ} 12.587$ (BRASIL, 2012) no tocante à melhoria dos serviços de circulação viária, a prefeitura municipal demonstrou interesse, nos últimos anos, na implantação de ciclofaixas para promover a multimodalidade de transportes. Apesar de ser relevante para a urbanização, a forma como esse elemento está sendo implantado tende a desfigurar a seção transversal das sarjetas, danificando o abaulamento necessário à correta condução da vazão (TEIXEIRA, 2017, p. 16).

Assim, este trabalho se destina a avaliar o desempenho hidráulico de sarjetas em oito quadras localizadas no bairro Aldeota, na cidade de Fortaleza (CE), comparando a situação ideal de projeto com aquela encontrada em campo. A escolha da área se justifica pelo elevado adensamento populacional e pela presença de edifícios comerciais, fatores que contribuem diretamente para a maior geração de escoamento superficial.

\section{Método}

O arquivo contendo as cotas topográficas, fundamentais para o cálculo da capacidade hidráulica e determinantes para o direcionamento das águas pluviais, foi obtido na Secretaria de Infraestrutura de Fortaleza (SEINF), sendo disponibilizado material cartográfico constituído de curvas de nível do terreno com equidistância de 5 metros. A partir desse arquivo, também se coletaram os dados de áreas e comprimentos das ruas.

Posteriormente, algumas visitas de campo foram realizadas na área de estudo para locação das bocas de lobo existentes em cada trecho e registro fotográfico da situação averiguada. Calcularam-se, então, os parâmetros hidráulicos das sarjetas, desconsiderando as obstruções no sistema de drenagem. Neste trabalho, a situação ideal de cálculo está sendo assumida como a de projeto, em conformidade com manuais de drenagem urbana, a exemplo do de Curitiba.

Em seguida, foram feitas simulações de intervenções no sistema de drenagem compreendendo as efetivas alterações das seções transversais, obtendo-se os parâmetros hidráulicos para a nova estimativa de vazão máxima possível sem o extravasamento do canal.

\section{Aspectos hidrológicos considerados para o dimensionamento}

Para estimar a vazão de pico da bacia, aplica-se o método racional, cuja equação é a seguinte:

$$
Q=0,278 \cdot \mathrm{C} \cdot \mathrm{i} \cdot \mathrm{A}
$$

Em que $Q$ é a vazão de pico $\left(\mathrm{m}^{3} / \mathrm{s}\right), C$ é o coeficiente de escoamento superficial, $i$ é a intensidade de chuva $(\mathrm{mm} / \mathrm{h})$ e $A$ é a área da bacia $\left(\mathrm{km}^{2}\right)$. 
O coeficiente de escoamento superficial pode ser obtido conforme a Tab. (1):

Tabela 1 - Valores de C por tipo de ocupação

\begin{tabular}{l|c}
\hline Descrição da área & C \\
\hline Área comercial & $0,70-0,90$ \\
Central & $0,50-0,70$ \\
Bairros & \\
\hline Área residencial & $0,35-0,50$ \\
Residências isoladas & $0,40-0,60$ \\
Unidades múltiplas (separadas) & $0,60-0,75$ \\
Unidades múltiplas (conjugadas) & $0,30-0,45$ \\
Lotes com >2.000 m² & $0,50-0,70$ \\
Áreas com apartamentos & \\
\hline
\end{tabular}

Fonte: Bidone e Tucci, 1995, adaptado, p. 88.

No âmbito deste trabalho, o coeficiente $\mathrm{C}$ se refere a área comercial central, sendo considerado o valor médio de 0,80 .

A intensidade de chuva foi estimada aplicando-se a relação IDF de Fortaleza. Essa equação foi elaborada por Silva, Júnior e Campos (2012), que analisaram 30 anos de registros de chuva e 611 hietogramas da estação climatológica da Universidade Federal do Ceará, utilizando durações de 5, 10, 20, 30, 45, 60 e 120 minutos. A relação IDF de Fortaleza é a Eq. (2):

$$
i=\frac{\left(2.345,29 \cdot T_{r}^{0,173}\right)}{(t+28,31)^{0,904}}
$$

Sendo $i$ a intensidade de chuva $(\mathrm{mm} / \mathrm{h}), T_{r}$ o período de retorno (anos) e to tempo de duração da chuva (min).

Para Bidone e Tucci (1995, p. 89-90), "o tempo de concentração inicial nos trechos de cabeceira de rede, que corresponde ao tempo de escoamento superficial pelos quarteirões, vias e sarjetas, é, muitas vezes, adotado como sendo de 10 minutos". Além disso, para pequenas bacias, considera-se que o tempo de duração da chuva é igual ao tempo de concentração. Segundo Tomaz (2002, p. 381), o valor de 10 minutos pode estar superestimado no caso de bacias muito impermeáveis e com grande declividade. Neste trabalho, considerou-se o tempo de concentração de partida de 5 minutos, haja vista a maior intensidade de chuva para menor duração.

O período de retorno a ser utilizado foi extraído da Tab. (2):

Tabela 2 - Períodos recomendados de acordo com o tipo de estrutura

\begin{tabular}{l|c}
\hline Tipo de estrutura & Período de retorno (anos) \\
\hline Bueiros em estradas com tráfego baixo & 5 a 10 \\
Bueiros em estradas com tráfego médio & 10 a 25 \\
Bueiros em estradas com tráfego intenso & 50 a 100 \\
Pontes de estrada secundária & 10 a 50 \\
Pontes de estrada principal & 50 a 100 \\
Bueiros para drenagem de fazenda & 5 a 50 \\
Drenagem urbana para cidades pequenas & 2 a 25 \\
Drenagem urbana para cidades grandes & 25 a 50 \\
Aeroportos com tráfego baixo & 5 a 10 \\
\hline
\end{tabular}

Fonte: Tomaz, 2002, adaptado, p. 68. 
Avaliação de desempenho hidráulico de sarjetas no sistema de drenagem urbana: um estudo no bairro Aldeota, em Fortaleza (CE)

Dessa forma, foi adotado período de retorno de 25 anos, relativo à drenagem urbana para grandes cidades.

\section{Especificações das sarjetas urbanas}

O Manual de drenagem urbana da região metropolitana de (SUPERINTENDÊNCIA DE DESENVOLVIMENTO DE RECURSOS HÍDRICOS E SANEAMENTO AMBIENTAL, 2002) considera duas hipóteses para o dimensionamento da capacidade de condução das sarjetas:

- A água escoando por toda a calha da rua;

- A água escoando somente pelas sarjetas.

Para o primeiro caso, admite-se a declividade da rua $\left(I_{r}\right)$ como sendo de $3 \%$ e a altura da lâmina d'água $\left(h_{1}\right)$ na sarjeta de $0,15 \mathrm{~m}$. Já para o segundo caso, a declividade da rua também é $3 \%$, mas a altura da lâmina d'água $\left(h_{2}\right)$ será de $0,10 \mathrm{~m}$, conforme pode ser visualizado na Fig. 1:

Figura 1 - Seção transversal da sarjeta conforme as hipóteses admitidas para o dimensionamento

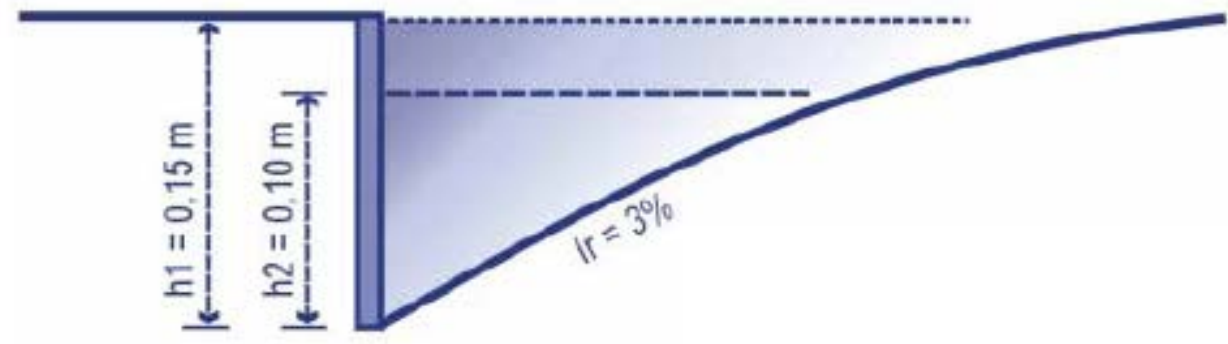

Fonte: Superintendência de Desenvolvimento de Recursos Hídricos e Saneamento Ambiente, 2002, p. 103.

O cálculo da capacidade teórica é dado pela fórmula de Manning, a seguir:

$Q=\frac{1}{n} \cdot R_{h}^{2 / 3} \cdot S^{1 / 2} \cdot A$

Em que é o coeficiente de rugosidade, é o raio hidráulico $(\mathrm{m})$, é a declividade $(\mathrm{m} / \mathrm{m})$ e é a área de drenagem $\left(m^{2}\right)$.

O coeficiente de rugosidade é dado pelo tipo de material com o qual a sarjeta é construída, sendo obtido pela Tab. (3):

Tabela 3 - Valores para coeficientes de rugosidade conforme material

\begin{tabular}{l|c}
\hline Características & $\mathbf{n}$ \\
\hline Canais retilíneos com grama de até $15 \mathrm{~cm}$ de altura & $0,30-0,40$ \\
Canais retilíneos com capins de até $30 \mathrm{~cm}$ de altura & $0,30-0,060$ \\
Galerias de concreto pré-moldado com bom acabamento & $0,011-0,014$ \\
Galerias de concreto moldado no local com formas metálicas simples & $0,012-0,014$ \\
Galerias de concreto moldado no local com formas de madeira & $0,015-0,020$ \\
Sarjetas em asfalto suave & 0,013 \\
Sarjetas em asfalto rugoso & 0,016 \\
Sarjetas em concreto suave com pavimento de asfalto & 0,014 \\
Sarjetas em concreto rugoso com pavimento de asfalto & 0,015 \\
Sarjetas em pavimento de concreto & $0,014-0,016$ \\
Pedras & 0,016 \\
\hline
\end{tabular}

Fonte: Superintendência de Desenvolvimento de Recursos Hídricos e Saneamento Ambiente, 2002, p. 103. 
Para este trabalho, foi adotado o coeficiente de rugosidade de 0,016 , referente ao pavimento de concreto. O raio hidráulico para as sarjetas, cuja seção transversal é aproximadamente um triângulo, é comumente adotado como a razão entre a área molhada e o perímetro molhado. Já a declividade longitudinal das ruas foi obtida pela razão entre a diferença de cotas do terreno e respectivo comprimento das ruas.

Assim, para averiguar se as sarjetas conseguem conduzir a água gerada pela chuva de projeto, é feita uma comparação entre as vazões de projeto e as capacidades teóricas das sarjetas. Caso as sarjetas consigam conduzir a água de forma eficiente, mas não haja boca de lobo em determinado trecho, a vazão será somada ao trecho subsequente, seguindo a orientação dada pelas cotas do terreno.

\section{3 Área de estudo}

A área selecionada para o estudo se localiza na Bacia da Vertente Marítima, compreendendo a faixa ao longo do litoral entre os rios Cocó e Ceará, inserida totalmente na área urbana de Fortaleza.

A topografia dessa bacia favorece o escoamento das águas para o mar, diretamente ou através de riachos. Os conflitos entre urbanização e meio natural são evidenciados por seu grande adensamento residencial.

A Figura 2 abaixo ilustra a localização da área de estudo.

Figura 2 - Localização da área de estudo

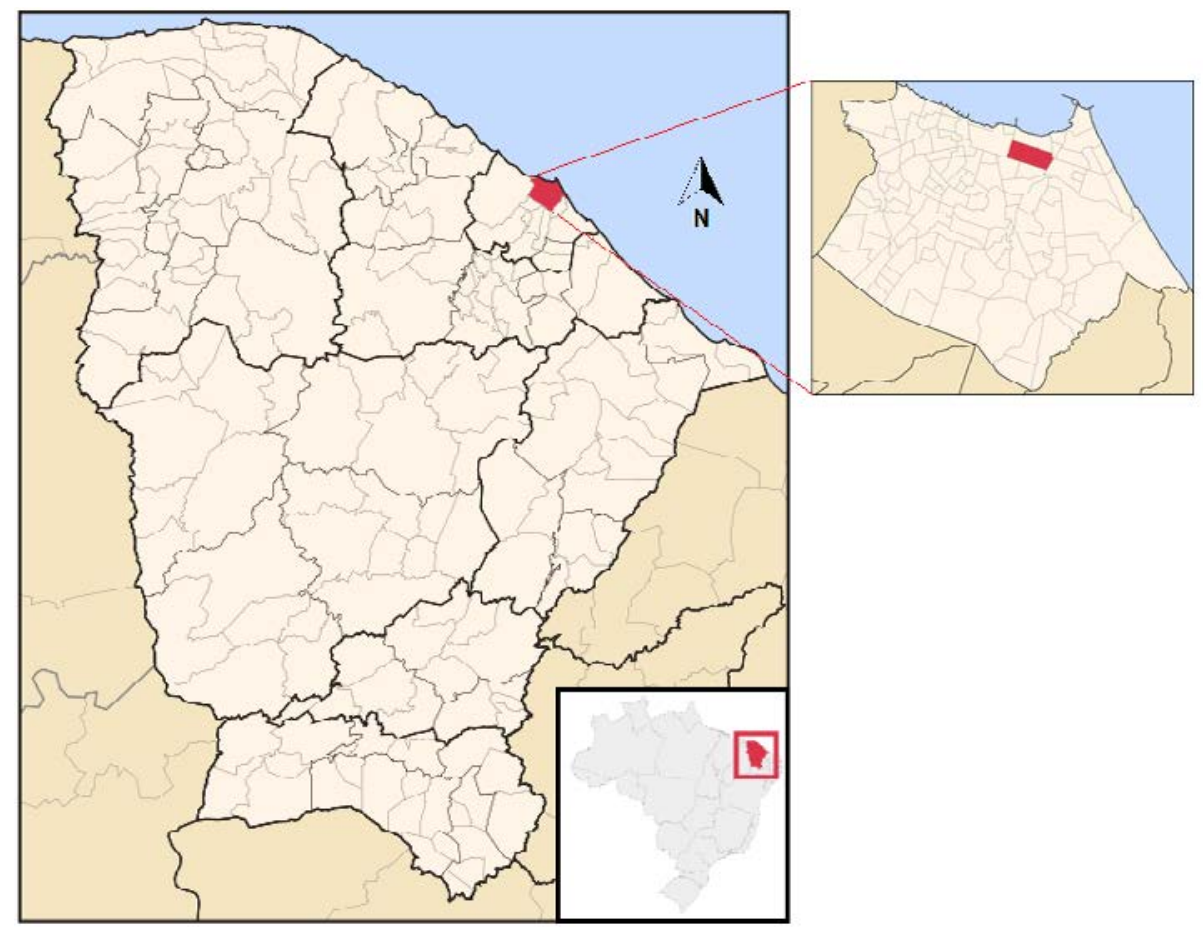

Fonte: Elaborado pelos autores, 2020

A sub-bacia compreende oito quadras cuja via central é a avenida Santos Dumont. Paralelas a esta estão rua Maria Tomázia, rua Desembargador Leite Albuquerque e a rua Joaquim Siqueira. Perpendicularmente, estão: avenida Desembargador Moreira, rua Barbosa de Freitas, rua Leonardo Mota, rua Vicente Leite e a rua Coronel Linhares. Essa configuração pode ser visualizada na Figura 3. 
Figura 3 - Delimitação da área de estudo

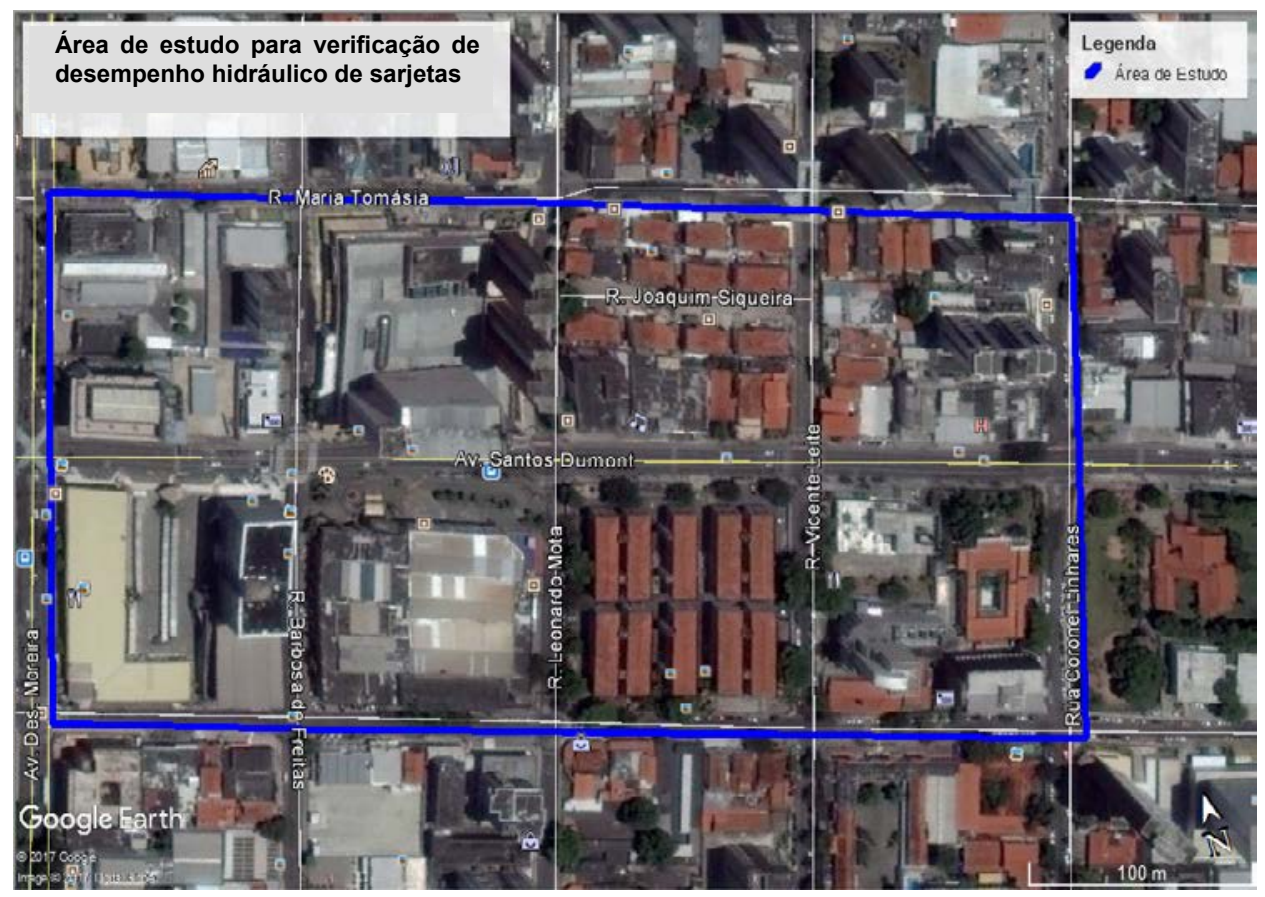

Fonte: Google Earth Pro ${ }^{\circledR}$, adaptado pelos autores, 2020.

A sub-bacia tem área total de, aproximadamente, $100.300 \mathrm{~m}^{2}$. As quadras apresentam aspectos geométricos bem semelhantes, cada uma delas com área de $10.600 \mathrm{~m}^{2}$.

Para o dimensionamento, aplicou-se a Eq. (3) assumindo regime de escoamento permanente uniforme.

As cotas (em metro) de cada encontro das vias da sub-bacia, as áreas das quadras e as larguras das vias (12 metros na avenida Santos Dumont e 8 metros nas demais vias), foram obtidas na Secretaria de Infraestrutura de Fortaleza (Seinf), conforme pode ser visualizado na Figura 4.

A área de contribuição para as sarjetas foi obtida considerand-se $25 \%$ da área das quadras, ou seja, aproximadamente $2.650 \mathrm{~m}^{2}$, assim como a área referente às ruas.

Figura 4 - Cotas do terreno da área de estudo

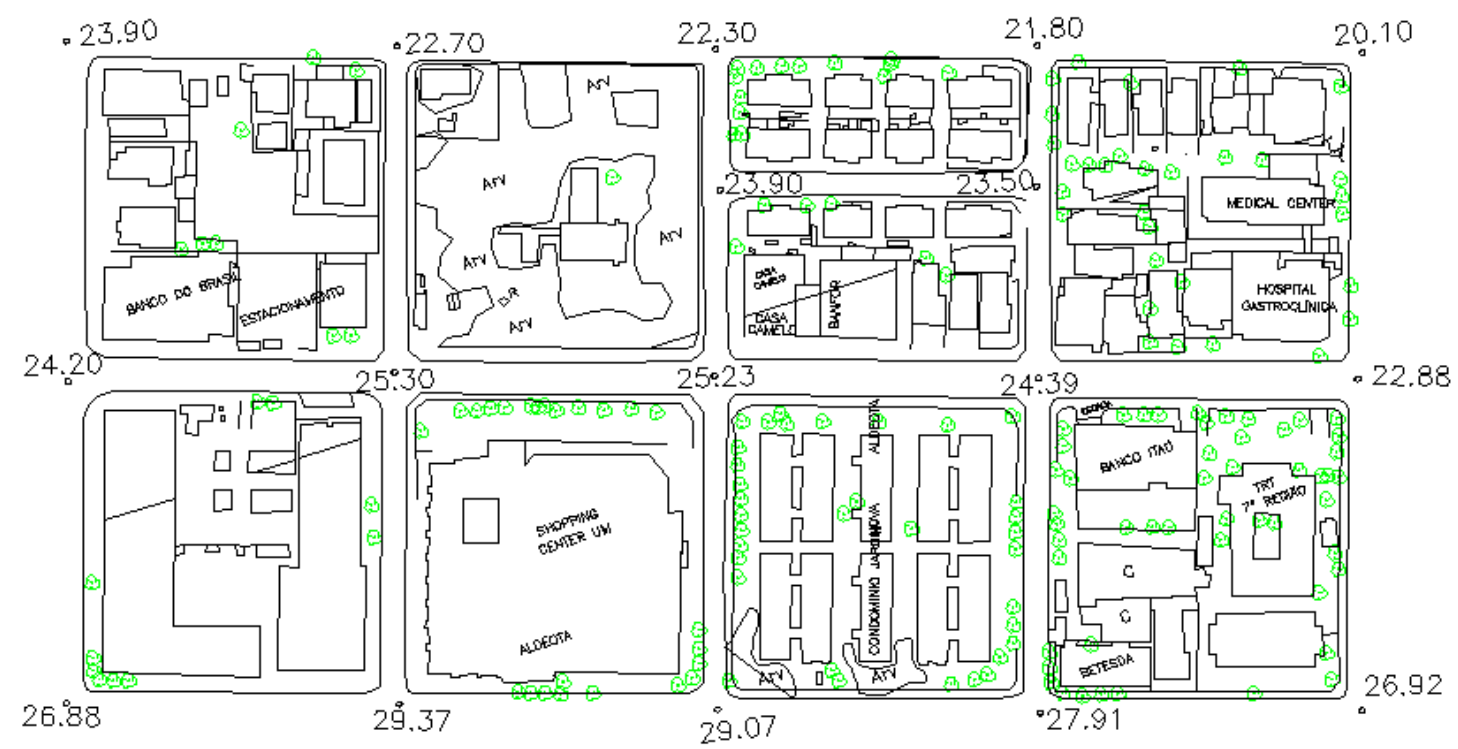

Fonte: SEINF, 2020. 


\section{Resultados e discussão}

31 Obtenção de parâmetros hidráulicos de sarjetas de projeto

Atribuindo a cada quadra e a cada trecho da área da subbacia a nomenclatura de Q1 a Q9 e de T1 a T25, obteve-se a Figura 5.

Figura 5 - Nomenclatura atribuída aos trechos e às quadras

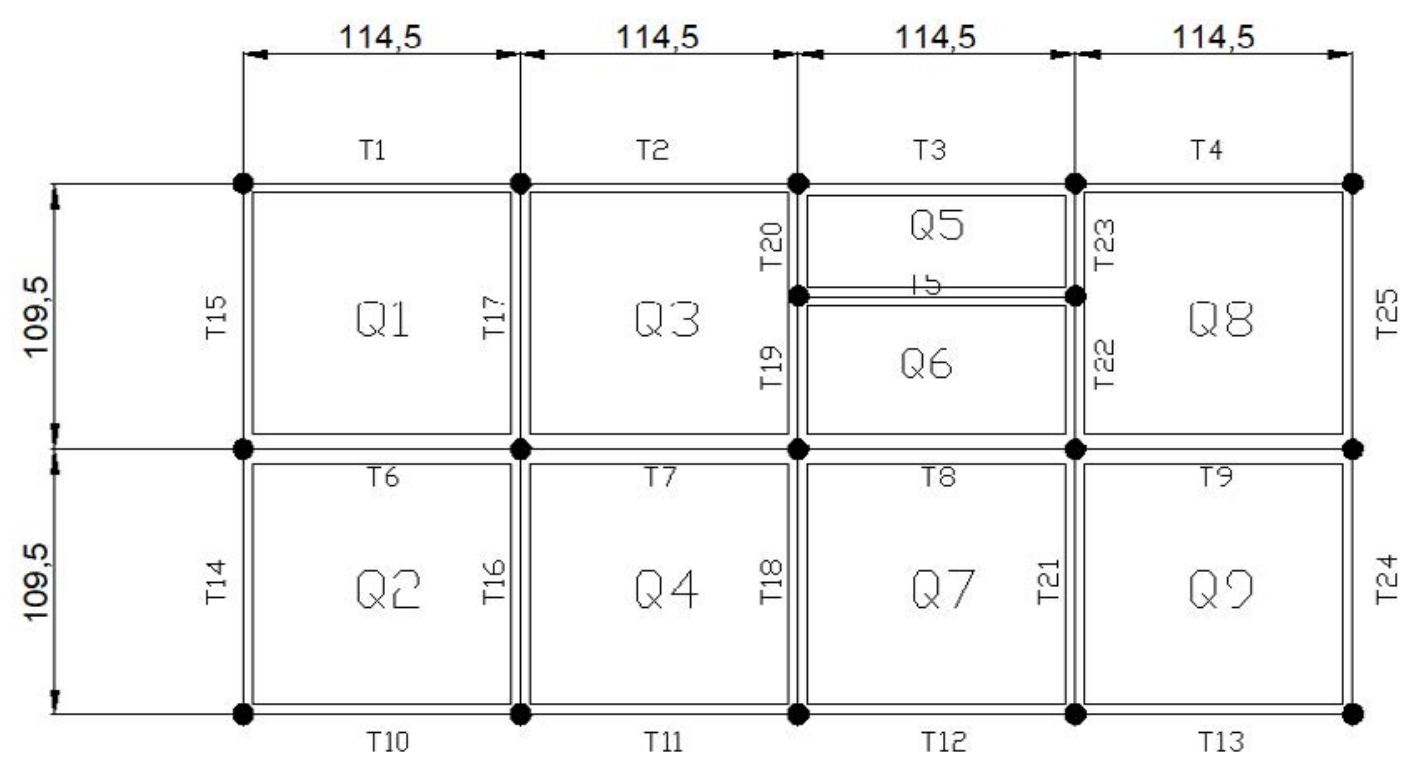

Fonte: Elaborado pelos autores, 2020.

Assumindo, de acordo com a Figura 1, a altura da lâmina d'água de 0,15 m e declividade transversal de $3 \%$, as capacidades teóricas das sarjetas calculadas estão dispostas na Tab. (4):

Tabela 4 - Capacidade teórica das sarjetas por trecho de acordo com a declividade longitudinal

\begin{tabular}{|c|c|c|c|c|c|}
\hline Identificação & $\begin{array}{l}\text { Declividade } \\
\qquad(\mathrm{m} / \mathrm{m})\end{array}$ & $\begin{array}{c}\text { Capacidade } \\
\text { teórica das } \\
\text { sarjetas }\left(\mathrm{m}^{3} / \mathrm{s}\right)\end{array}$ & Identificação & $\begin{array}{l}\text { Declividade } \\
\qquad(\mathrm{m} / \mathrm{m})\end{array}$ & $\begin{array}{l}\text { Capacidade teórica } \\
\text { das sarjetas }\left(\mathrm{m}^{3} / \mathrm{s}\right)\end{array}$ \\
\hline $\mathrm{T} 1$ & 0,0105 & 0,418 & T15 & 0,0027 & 0,214 \\
\hline $\mathrm{T} 2$ & 0,0035 & 0,241 & T16 & 0,0372 & 0,788 \\
\hline T3 & 0,0044 & 0,270 & $\mathrm{~T} 17$ & 0,0237 & 0,630 \\
\hline $\mathrm{T} 4$ & 0,0148 & 0,498 & $\mathrm{~T} 18$ & 0,0351 & 0,765 \\
\hline T5 & 0,0035 & 0,241 & T19 & 0,0211 & 0,594 \\
\hline T6 & 0,0096 & 0,400 & T20 & 0,0353 & 0,767 \\
\hline $\mathrm{T7}$ & 0,0006 & 0,101 & T21 & 0,0321 & 0,733 \\
\hline T8 & 0,0073 & 0,350 & T22 & 0,0141 & 0,486 \\
\hline T9 & 0,0132 & 0,469 & T23 & 0,0375 & 0,791 \\
\hline T10 & 0,0217 & 0,603 & T24 & 0,0369 & 0,785 \\
\hline $\mathrm{T} 11$ & 0,0026 & 0,209 & T25 & 0,0254 & 0,651 \\
\hline T12 & 0,0101 & 0,411 & T19/T20 & 0,0268 & 0,668 \\
\hline T13 & 0,0086 & 0,380 & \multirow{2}{*}{$\mathrm{T} 22 / \mathrm{T} 23$} & \multirow{2}{*}{0,0237} & \multirow{2}{*}{0,628} \\
\hline T14 & 0,0245 & 0,639 & & & \\
\hline
\end{tabular}

Fonte: Elaborado pelos autores, 2020. 


\section{Comparativo entre a situação de projeto e a situação encontrada em campo}

A Figura 6 apresenta as características geométricas das quadras, as cotas de esquina e a localização das bocas de lobo.

Conforme anteriormente esclarecido, e não estando disponível o projeto original das sarjetas na área de estudo, a situação de projeto considerada para os cálculos hidráulicos leva em conta a sarjeta padrão, como mostrada na Figura 1, assumindo-se a altura da lâmina d'água de $0,15 \mathrm{~m}$ e a declividade transversal das ruas de $3 \%$.

Figura 6 - Características geométricas das quadras (cont.)
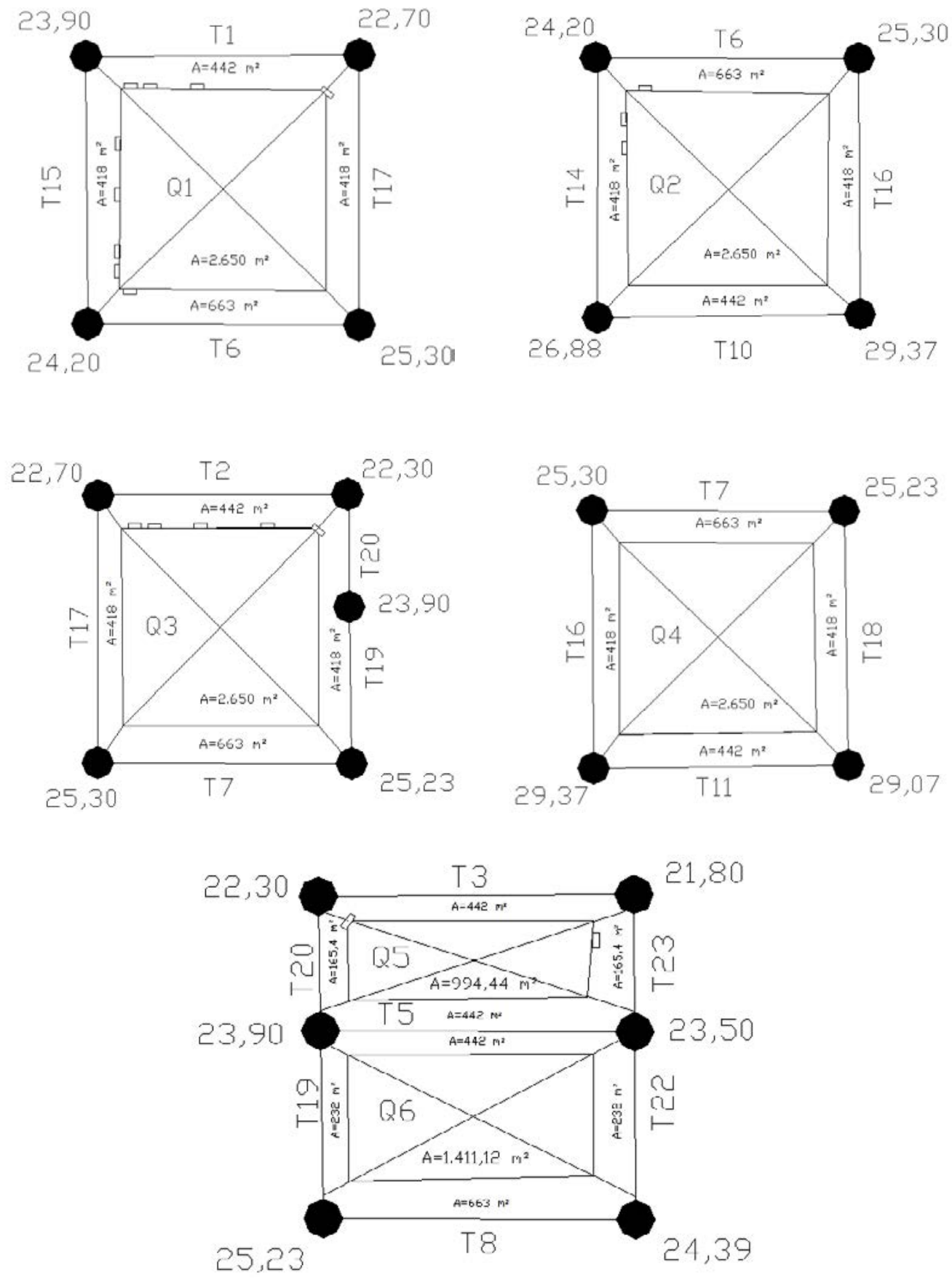
Figura 6 - Características geométricas das quadras (conclusão)
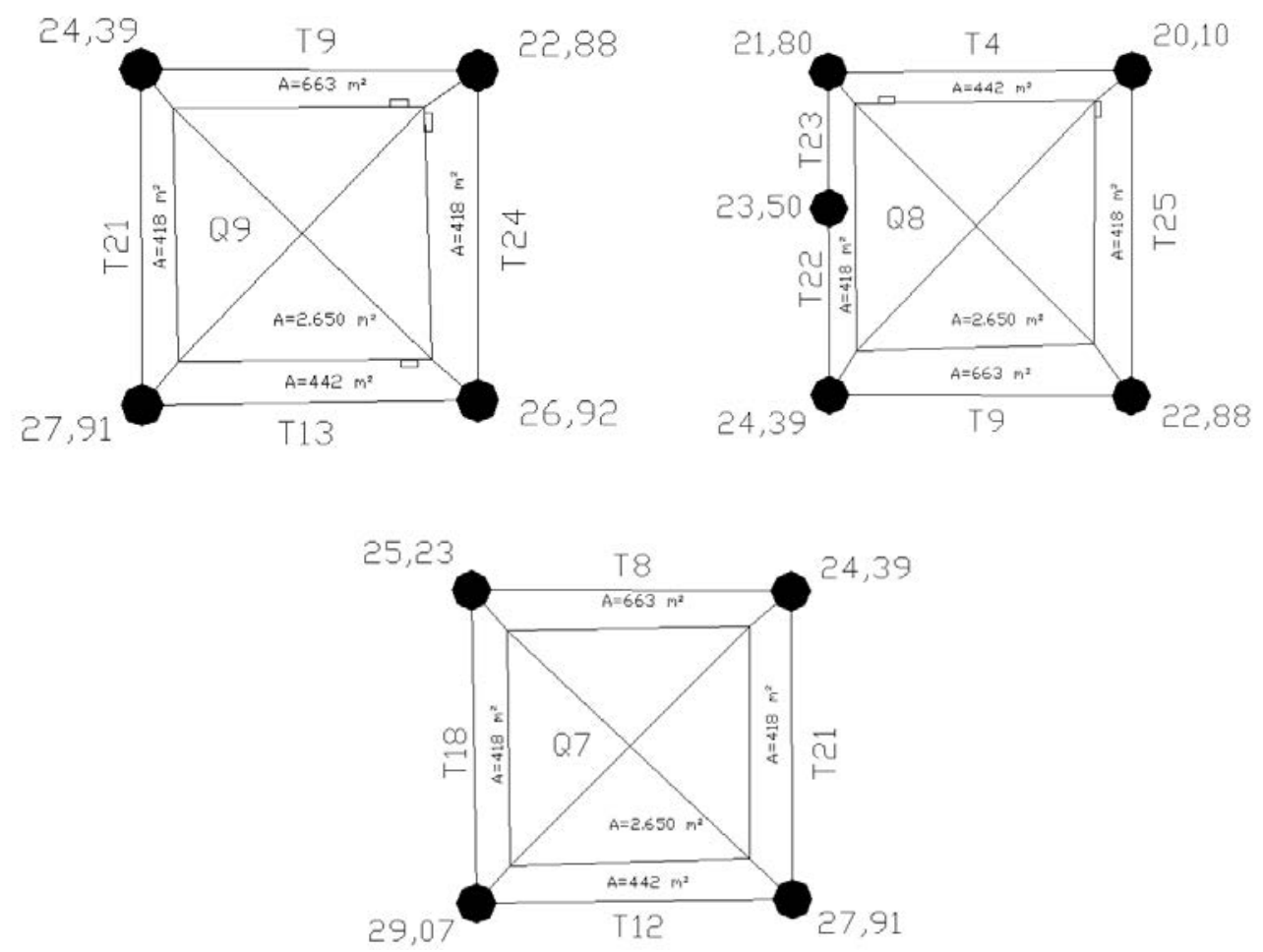

Fonte: Elaborado pelos autores, 2020.

A Tabela 5 traz as vazões de projeto (Qp), assim como as capacidades teóricas das sarjetas na situação de projeto e nas simulações, em que foi reduzida a altura da lâmina d'água, antes considerada $0,15 \mathrm{~m}$ na situação de projeto, adotando-se, a depender da gravidade de danificação às sarjetas, $0,13 \mathrm{~m}, 0,12 \mathrm{~m}$ ou $0,10 \mathrm{~m}$.

Tabela 5 - Comparativo entre as vazões de projeto e capacidades teóricas das sarjetas de cada quadra

\begin{tabular}{|c|c|c|c|c|c|c|c|c|c|}
\hline Quadra & Trecho & $\mathrm{Qp}\left(\mathrm{m}^{3} / \mathrm{s}\right)$ & $\begin{array}{l}\text { Qc }\left(\mathrm{m}^{3} / \mathrm{s}\right) \\
\text { - Projeto }\end{array}$ & $\begin{array}{l}\text { Qc (m³/s) - } \\
\text { Simulação }\end{array}$ & Quadra & Trecho & $\begin{array}{c}\mathrm{Qp} \\
\left(\mathrm{m}^{3} / \mathrm{s}\right)\end{array}$ & \begin{tabular}{|l|} 
Qc $\left(\mathrm{m}^{3} / \mathrm{s}\right)$ \\
- Projeto \\
\end{tabular} & $\begin{array}{l}\text { Qc }\left(m^{3} / s\right)- \\
\text { Simulação }\end{array}$ \\
\hline \multirow{4}{*}{ Q1 } & $\mathrm{T} 1$ & 0,118 & 0,418 & 0,286 & \multirow{4}{*}{ Q6 } & \multirow{2}{*}{ T8 } & \multirow{2}{*}{0,079} & \multirow{2}{*}{0,350} & \multirow{2}{*}{0,239} \\
\hline & T6 & 0,127 & 0,400 & 0,273 & & & & & \\
\hline & T15 & 0,117 & 0,214 & 0,073 & & \multirow{2}{*}{ T22 } & \multirow{2}{*}{0,063} & \multirow{2}{*}{0,486} & \multirow{2}{*}{0,268} \\
\hline & T17 & 0,117 & 0,630 & 0,630 & & & & & \\
\hline \multirow{4}{*}{ Q2 } & T6 & 0,127 & 0,400 & 0,221 & \multirow{4}{*}{ Q8 } & T4 & 0,118 & 0,498 & 0,498 \\
\hline & T10 & 0,118 & 0,603 & 0,204 & & T9 & 0,127 & 0,469 & 0,259 \\
\hline & T14 & 0,117 & 0,639 & 0,639 & & T22/T23 & 0,117 & 0,628 & 0,213 \\
\hline & T16 & 0,117 & 0,788 & 0,788 & & T25 & 0,117 & 0,651 & 0,221 \\
\hline \multirow{2}{*}{ Q3 } & $\mathrm{T7}$ & 0,127 & 0,101 & 0,069 & \multirow{6}{*}{ Q9 } & T9 & 0,127 & 0,469 & 0,159 \\
\hline & T19/T20 & 0,117 & 0,668 & 0,456 & & \multirow{2}{*}{ T13 } & \multirow{2}{*}{0,118} & \multirow{2}{*}{0,380} & \multirow{2}{*}{0,380} \\
\hline \multirow{4}{*}{ Q4 } & $\mathrm{T} 7$ & 0,127 & 0,101 & 0,034 & & & & & \\
\hline & T11 & 0,118 & 0,209 & 0,115 & & \multirow{2}{*}{ T21 } & \multirow{2}{*}{0,117} & \multirow{2}{*}{0,733} & \multirow{2}{*}{0,248} \\
\hline & T16 & 0,117 & 0,788 & 0,788 & & & & & \\
\hline & T18 & 0,117 & 0,765 & 0,422 & & T24 & 0,117 & 0,785 & 0,433 \\
\hline
\end{tabular}

Fonte: Elaborado pelos autores, 2020. 
A Quadra 1 possui nove bocas de lobo e a capacidade teórica das sarjetas é superior às vazões de projeto, acarretando em condução de água superficial eficiente pelas sarjetas ao assumir os parâmetros considerados para a situação de projeto. Com a simulação das intervenções de campo, os trechos T1, T6 e T15 se encontraram danificados, sendo suas lâminas d'água reduzidas para $0,13 \mathrm{~m}, 0,13 \mathrm{~m}$ e $0,10 \mathrm{~m}$, respectivamente. Devido a essa redução, o trecho T15 passa a não comportar a vazão gerada pela água precipitada, gerando escoamento superficial excessivo. Apesar disso, essa condição é amortecida pela quantidade de bocas de lobo existentes no trecho.

No caso da Quadra 2, o trecho T10 consegue conduzir a vazão de projeto, mas, pelo fato de não haver boca de lobo, a vazão soma-se à do trecho seguinte, que, nesse caso, é o T14. As vazões de projeto de T10 e T14 somadas (aproximadamente $0,235 \mathrm{~m}^{3} / \mathrm{s}$ ) não superam a capacidade teórica de T14, e são conduzidas a duas bocas de lobo encontradas em campo. Assim, não há pontos de alagamento nesses dois trechos. Com as simulações realizadas para a situação encontrada em campo, o trecho T10 ainda consegue comportar a vazão de projeto, apesar de ter havido uma redução da lâmina d'água de $0,15 \mathrm{~m}$ para $0,10 \mathrm{~m}$. Além disso, as vazões somadas de T10 e T14 não superam a capacidade teórica de T14, já que esse trecho se encontra numa situação conservada, conforme observado em campo. O trecho T6, que se encontra danificado e foi simulado com uma redução de $0,15 \mathrm{~m}$ para $0,12 \mathrm{~m}$, não consegue comportar as vazões somadas de T6 e T16.

Para a Quadra 3, foram selecionados dois trechos para averiguar a situação das sarjetas na situação de projeto. A vazão de projeto no trecho T7 supera a capacidade teórica, gerando alagamentos. Como não há boca de lobo no trecho, a vazão será somada à do trecho T19/T20. As duas vazões somadas (aproximadamente $0,244 \mathrm{~m}^{3} / \mathrm{s}$ ) não superam a capacidade teórica de T19/T20, não havendo, teoricamente, pontos de alagamento. Para a situação de campo, o trecho T7 apresenta problemas ainda maiores de alagamento quando comparado à situação de projeto com a simulação das intervenções. Como não há boca de lobo, a vazão será somada à de T19/T20, o que não supera a capacidade teórica da sarjeta, apesar das simulações de redução de $0,15 \mathrm{~m}$ para $0,13 \mathrm{~m}$.

$\mathrm{Na}$ Quadra 4, a sarjeta do trecho T7 não comporta a vazão de projeto, gerando alagamentos. Pelo fato de não haver bocas de lobo encontradas in loco, toda a quadra apresenta pontos de inundação, mesmo com a capacidade de condução hidráulica das sarjetas dos demais trechos funcionando adequadamente. Ao realizarse as simulações, o problema de inundações por ausência de bocas de lobo é ainda mais evidenciado com a redução do desempenho hidráulico das sarjetas, mesmo com as capacidades teóricas dos trechos T16 e T18 sendo maiores que as vazões de projeto. O trecho T11 não comporta a vazão gerada pela precipitação após a simulação de redução da lâmina d'água de $0,15 \mathrm{~m}$ para $0,12 \mathrm{~m}$.

$\mathrm{Na}$ Quadra 5, na situação de projeto considerada, os trechos conseguem escoar a água adequadamente pelas sarjetas até as bocas de lobo. Os trechos T8 e T22 comportam as vazões de projeto, mas não há bocas de lobo na Quadra 6, o que gera pontos de alagamento. Na situação de campo, nos trechos analisados da Quadra 6, como não há bocas de lobo, os problemas de alagamento são ainda mais agravados. Apesar das reduções, as sarjetas conseguem comportar as vazões geradas pela precipitação, mas não têm condições de direcionar a água para escoamento nas bocas de lobo.

A Quadra 7 apresenta situação semelhante à da Quadra 4, com ausência de bocas de lobo. Assim, mesmo com as sarjetas conduzindo a água precipitada de forma eficiente, há pontos de alagamento na quadra.

A Quadra 8, em situação de projeto assumida, consegue conduzir adequadamente a água pelas sarjetas, pois a ausência de bocas de lobo em T22/T23 e T9 é suprida pelas dos trechos subsequentes, sendo as vazões somadas com valor inferior à capacidade teórica das sarjetas. Ao simularem-se as intervenções encontradas em campo, observa-se que a sarjeta do trecho T4 se encontra conservada e, portanto, consegue comportar as vazões somadas de T4 e T22/T23. Com a redução de $0,15 \mathrm{~m}$ para $0,10 \mathrm{~m}$ no trecho T25, ocorrem situações de alagamento não observadas na situação de projeto, pois a capacidade teórica da sarjeta no trecho é superada pelo somatório das vazões de T9 e T25. 
Na Quadra 9, os trechos T13 e T24 conseguem conduzir a água precipitada, sendo suficiente uma boca de lobo (encontradas in loco para cada um dos trechos) para comportar o escoamento superficial gerado. 0 trecho T21 também comporta a vazão de projeto e sua vazão é somada ao trecho T9, resultando em $0,244 \mathrm{~m}^{3} / \mathrm{s}$ aproximadamente. A capacidade teórica da sarjeta do trecho é superior ao somatório de vazões, que consegue conduzir a água até a boca de lobo. Portanto, não há pontos de alagamento na quadra na situação de projeto. Realizando as simulações de redução de seção transversal, observa-se que não há alagamentos nos trechos T13, T21 e T24, mas, como não há boca de lobo em T21, sua vazão é somada ao trecho T9. A redução da lâmina d'água nesse trecho, de $0,15 \mathrm{~m}$ para $0,10 \mathrm{~m}$, faz com que as vazões somadas superem a capacidade teórica da sarjeta, que apresenta problemas de inundação, não observados na condição anterior.

\section{Registro fotográfico coletado}

Para ilustrar algumas das situações encontradas durante as visitas à área em estudo, a Figura 7 traz a representação esquemática das quadras e fotos de três trechos, demonstrando a condição precária e, portanto, a reduzida capacidade de condução de vazão de projeto.

Figura 7 - Registro fotográfico dos trechos T6, T9 e T25

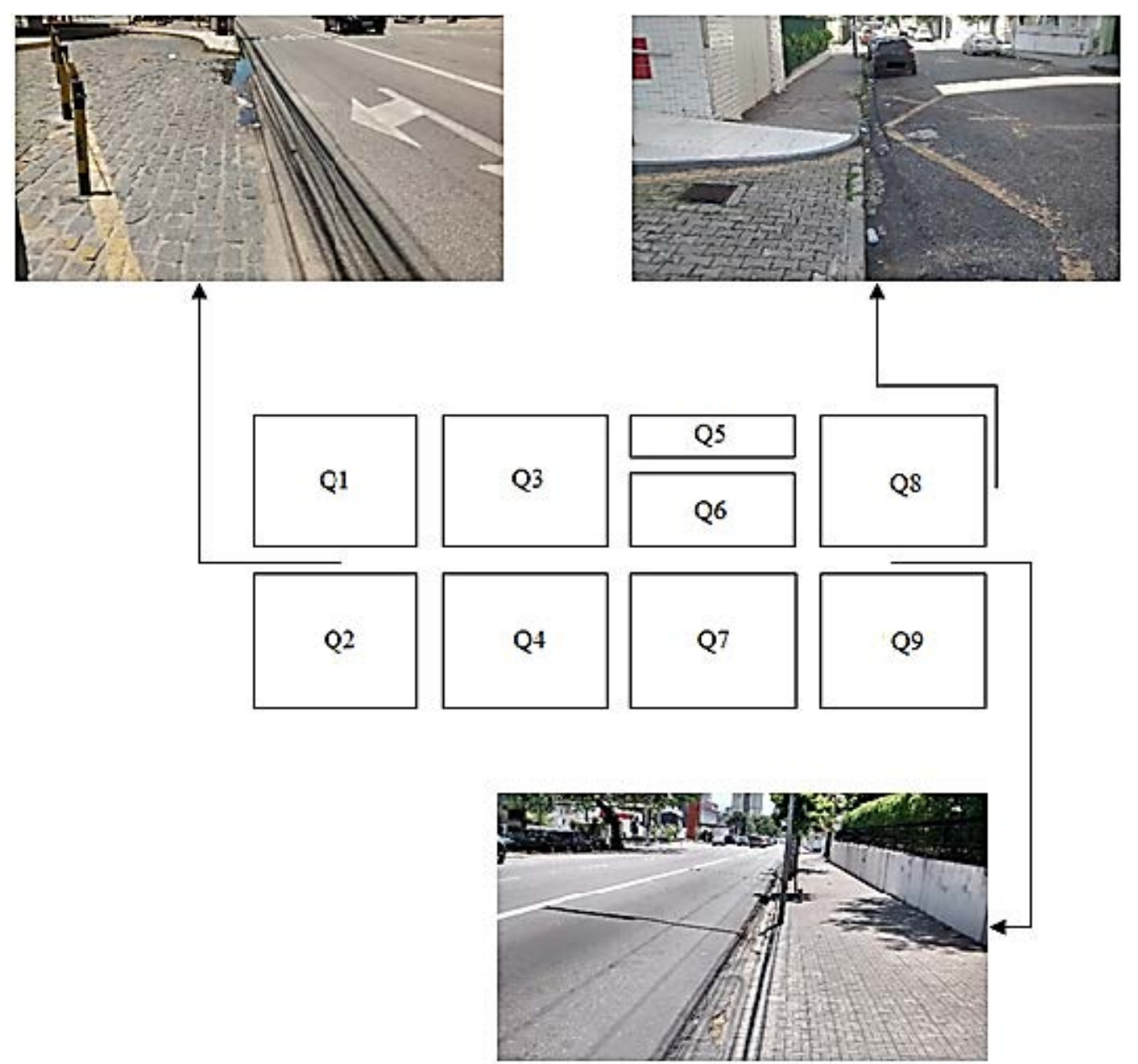

Fonte: Elaborado pelos autores, 2020. 


\section{Síntese gráfica dos resultados obtidos}

De forma a demonstrar o impacto gerado pela redução da capacidade hidráulica, causada pelas intervenções nas sarjetas, foi elaborada a Figura 8:

Figura 8 - Comparação entre as capacidades teóricas das sarjetas nas duas situações consideradas

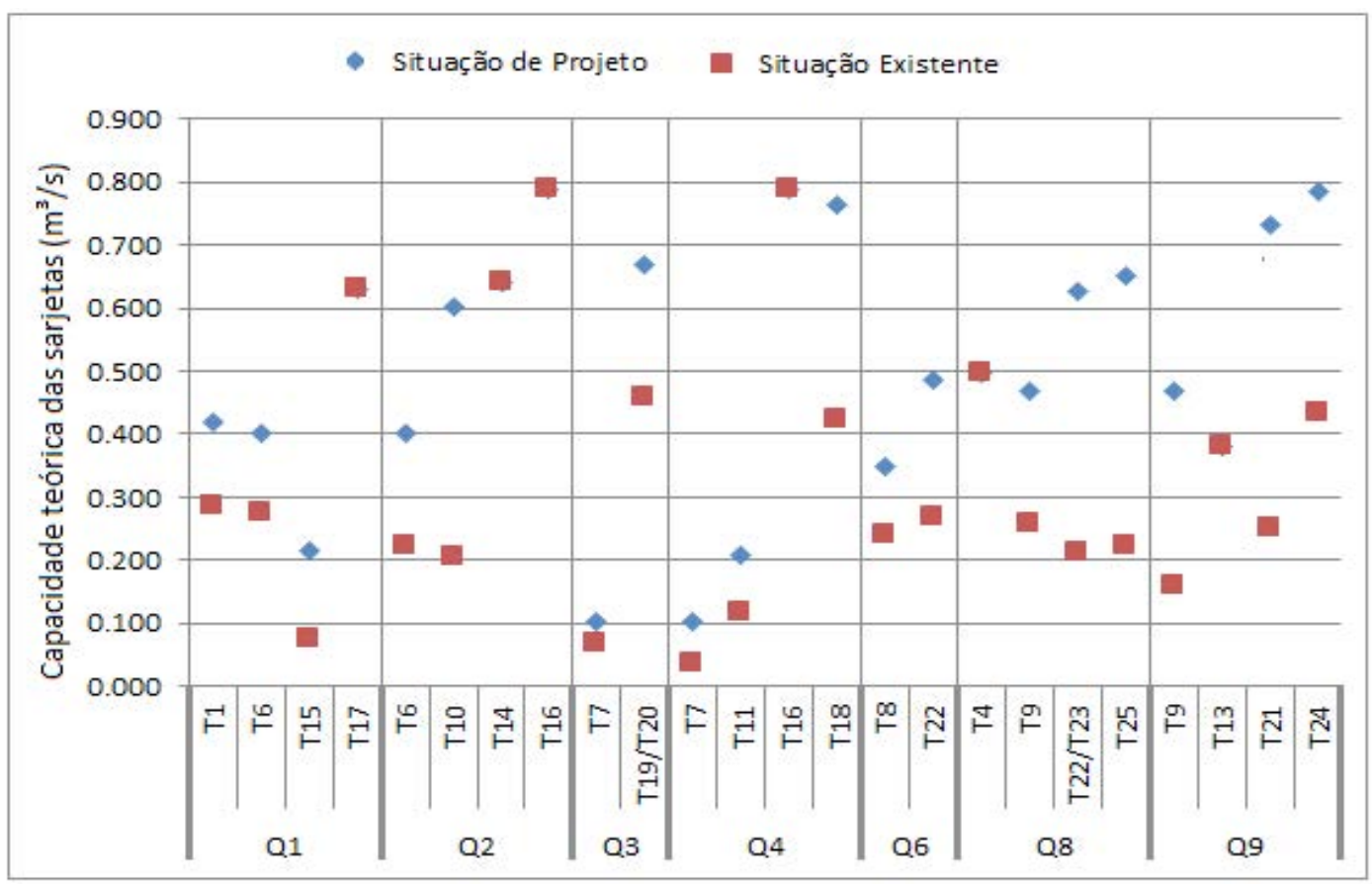

Fonte: Elaborado pelos autores, 2020.

As simulações realizadas levaram em conta as reduções existentes nas seções transversais das sarjetas que influenciam na área molhada e, por consequência, no raio hidráulico e na capacidade de escoamento.

Observando a Figura 8 e fazendo a correlação com a Tab. (4), pode-se notar que os trechos com maior redução de capacidade hidráulica são os que apresentam as maiores declividades, já que a área molhada é diretamente proporcional à capacidade teórica das sarjetas. Portanto, os trechos de menores declividades não tiveram uma redução significativa em sua capacidade de condução, não sendo afetados por problemas de enchentes como os demais.

Outra forma de realizar comparações entre as duas situações é através da Eq. (4):

$$
D=\frac{Q_{\text {proj }}-Q_{\text {exist }}}{Q_{\text {proj }}}
$$

Em que é a dispersão entre os resultados, Qproj é a capacidade teórica das sarjetas na condição de projeto assumida e Qexist é a capacidade na condição existente.

O resultado da aplicação da Eq. (4), considerando a média dos trechos pertencentes a cada quadra, pode ser observado na Figura 9: 
Figura 9 - Dispersões entre os resultados de projeto e de simulação por quadra

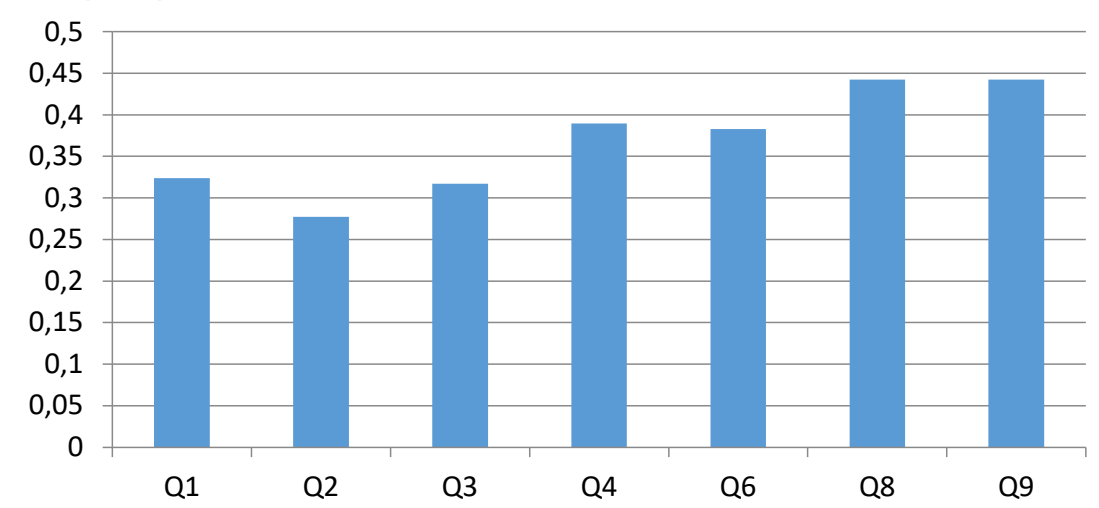

Fonte: Elaborado pelos autores, 2020.

Quanto menor a dispersão, mais próxima a sarjeta consegue operar com sua capacidade de condução hidráulica, conforme a Figura 1. Portanto, pelo que se depreende da Figura 12, a Quadra 2 é aquela cujas sarjetas mais se aproximam das condições de projeto consideradas, conseguindo alcançar o desempenho hidráulico previsto de forma mais satisfatória. Em situação mais precária, por outro lado, encontram-se as sarjetas das Quadras 8 e 9, que conseguem escoar, em média, pouco mais de $55 \%$ da vazão de projeto nesse caso, o volume excedente do escoamento superficial passa a ocupar parte significativa da via de tráfego, comprometendo, consequentemente, a circulação veicular e de pessoas.

\section{Conclusão}

O problema de enchentes urbanas na área de estudo é agravado pela deficiência de manutenção e conservação dos elementos estruturais existentes. Atenta-se, então, para a necessidade de se preservarem as condições de projeto, desde a sua implantação física e ao longo de toda a vida útil, além do adequado tratamento e acondicionamento dos resíduos sólidos.

Em termos de projeto, as obstruções observadas durante a execução deste trabalho geram acúmulo de água precipitada nas malhas viárias, e as galerias pluviais, que deveriam acomodar essas vazões, acabam se tornando estruturas superdimensionadas ao operarem com aproveitamento abaixo de sua capacidade.

O satisfatório desempenho dos equipamentos urbanos, incluindo aqueles relacionados à drenagem, demanda o efetivo e sistemático gerenciamento da manutenção e conservação, promovendo o escoamento seguro das águas de chuva e, dessa maneira, contribuindo para a saúde coletiva e o bem-estar geral da população.

\section{Referências}

BIDONE, Francisco R. A.; TUCCI, Carlos E. M. Microdrenagem. In: TUCCI, Carlos E. M. (org.); PORTO, Rubem La Laina (org.); BARROS, Mário T. de (org.). Drenagem urbana. 1. ed. Porto Alegre: Editora da Universidade, 1995. cap. 3. p. 77-105.

BRASIL. Lei $\mathbf{n}^{\circ}$ 12.587, de 3 de janeiro de 2012. Institui as diretrizes da Política Nacional de Mobilidade Urbana. Disponível em: http://www.planalto.gov.br/ccivil_03/_ato2011-2014/2012/lei/l12587.htm. Acesso em: 7 abr. 2020.

BRASIL. Manual de Saneamento. 3. ed. Brasília: Funasa, 2007. 408 p. Disponível em https://wp.ufpel.edu. br/ccz/files/2016/03/FUNASA-MANUAL-SANEAMENTO.pdf. Acesso em: 9 abr. 2020. 
GOOGLE. Google Earth Pro ®. 2020. Disponível em: https://www.google.com.br/earth/download/gep/ agree.html. Acesso em: 7 abr. 2020.

LIMA, Gabriel Henrique Arruda Tavares de. Dimensionamento do sistema de drenagem pluvial para o loteamento Santa Bárbara em Centralina-MG Uberlândia. 2019. Trabalho de Conclusão de Curso (Bacharelado em Engenharia Civil) - Universidade Federal de Uberlândia, Uberlândia, 2019. Disponível em: https://repositorio.ufu.br/bitstream/123456789/26152/4/DimensionamentoSistemaDrenagem.pdf. Acesso em: 6 abr. 2020.

SILVA, Francisco Osny Enéas da; PALÁCIO JUNIOR, Francisco Flávio Rocha; CAMPOS, José Nilson Bezerra. Equação de chuvas para Fortaleza CE com dados do pluviógrafo da UFC. Revista DAE, Fortaleza, v. 1491, n. 192, p. 48-59, 2012. Disponível em: http://revistadae.com.br/artigos/artigo_ edicao_192_n_1491.pdf. Acesso em: 7 abr. 2020.

SUPERINTENDÊNCIA DE DESENVOLVIMENTO DE RECURSOS HÍDRICOS E SANEAMENTO AMBIENTAL (Paraná). Manual de drenagem urbana da região metropolitana de Curitiba. Curitiba: SUDERHSA, 2002. Disponível em: http://www.aguasparana.pr.gov.br/arquivos/File/pddrenagem/volume6/ mdu_versao01.pdf. Acesso em: 9 abr. 2020.

TEIXEIRA, Lucas Florêncio da Cunha. Avaliação do desempenho hidráulico de sarjetas no sistema de drenagem de Fortaleza. 2017. 66 f. Trabalho de Conclusão de Curso (Bacharelado em Engenharia Civil) Universidade de Fortaleza, Fortaleza, 2017.

TOMAZ, P. Cálculos hidrológicos e hidráulicos para obras municipais. São Paulo: Navegar, 2002. 422p. Disponível em: http://wiki.urca.br/dcc/lib/exe/fetch.php?media=livro10_calculos_hidrologicos-ler.pdf. Acesso em: 9 abr. 2020.

\section{Sobre os autores}

Lucas Florêncio da Cunha Teixeira

Mestrando na área de Recursos Hídricos pelo Programa de Pós-Graduação em Engenharia Civil da Universidade Federal do Ceará. Graduado em Engenharia Civil pela Universidade de Fortaleza (2017).

Anísio de Sousa Meneses Filho

Mestre em Engenharia Civil pelo Programa de Pós-Graduação em Engenharia Civil da Universidade Federal (1991). Graduado em Engenharia Civil pela Universidade Federal do Piauí (1986) e, atualmente, professor do Centro de Ciências Tecnológicas da Universidade de Fortaleza.

Recebido em: 10.04 .2020

Aceito em: 14.05.2020 